\title{
LA VALORACIÓN PROBATORIA Y LA PRUEBA DE OFICIO COMO APROXIMACIÓN A LA GNOSEOLOGÍA INDUCTIVA EN EL PROCESO CIVIL
}

\author{
Sergio Roberto Salas Villalobos* \\ Universidad de Lima, Lima, Perú \\ ssv@salasabogados.com.pe \\ Recibido: 18/2/2021 Aprobado: 25/2/2021 \\ doi: https://doi.org/10.26439/iusetpraxis2021.n052.5220
}

\begin{abstract}
RESUMEN. La prueba de oficio en el proceso civil responde a la necesidad de arribar a la máxima aproximación de certeza de las premisas planteadas por las partes. La aporta el juez cuando este advierte la ausencia de un medio de prueba que es necesario para resolver el conflicto, pero que las partes no han podido impulsar. Antes de ello, el juez debe realizar el ejercicio de extraer el conocimiento contenido en los medios probatorios que sí se han podido actuar y relacionarlos para adquirir un conocimiento único que implique la conclusión del proceso. Solo cuando no es posible extraer ese conocimiento único mediante la valoración conjunta de los medios de prueba, el juez impulsará la prueba de oficio. El presente trabajo desarrolla el pensamiento de Perfecto Andrés Ibáñez, jurista y juez español, quien trata este mecanismo de la prueba de oficio como una inducción al proceso, un conocimiento nuevo y necesario para arribar a una conclusión lógica, y lo denomina gnoseología inductiva. El propósito es, entonces, plantear una propuesta teórica de la prueba de oficio, al margen de su tratamiento jurisdiccional y doctrinariamente clásico.
\end{abstract}

PALABRAS CLAVE: valoración conjunta de los medios probatorios / verdad material / máxima aproximación de certeza / prueba vs. contraprueba / el contradictorio / etapas del proceso / inferencia / gnoseología inductiva

\footnotetext{
* Abogado por la Universidad Nacional Mayor de San Marcos. Juez superior de la Corte Superior de Lima (1994-2008). Presidente de la Corte Superior de Lima (2001-2002). Catedrático de la Universidad de Lima en Derecho Procesal Civil y Derecho Judicial. Profesor en la Academia de la Magistratura y la Escuela Nacional de Control. Socio en Salas Abogados.
} 


\title{
WEIGHTING OF EVIDENCE AND PRUEBA DE OFICIO AS AN APPROACH TO INDUCTIVE GNOSEOLOGY IN CIVIL PROCEEDINGS
}

\begin{abstract}
The prueba de oficio in civil proceedings responds to the need for premises raised by the parties to arrive at the highest degree of certainty. The judge provides it when $\mathrm{s} /$ he notices the absence of a means of evidence that is necessary to resolve the dispute which the parties have not been able to put forward. However, prior to this, the judge must have extracted the knowledge from the means of evidence presented by the parties, and have related them to acquire a unique knowledge that results in the conclusion of the proceeding. Only when it is not possible to extract this unique knowledge through the joint assessment of the means of evidence, the judge will encourage the prueba de oficio. This paper applies the thinking of Perfecto Andrés Ibáñez, a Spanish jurist and judge, who treats the prueba de oficio as a way of inducing new and necessary knowledge in the proceeding to arrive at a logical conclusion which he calls "inductive gnoseology." The purpose of this research is consequently to propose a theoretical approach to the prueba de oficio, apart from its jurisdictional and doctrinally classical treatment.
\end{abstract}

KEYWORDS: joint assessment of the means of evidence / material truth / maximum approximation of certainty / evidence vs. counterevidence / debate between the parties / stages of the proceedings / inference / inductive gnoseology 


\section{INTRODUCCIÓN}

Uno de los aspectos trascendentales en la práctica procesal es la valoración probatoria. Sobre ello se centra la parte más activa del proceso, por cuanto implica no solo pericia en los agentes procesales sobre "cómo probar", sino también con respecto a cómo ejercer esa práctica de conocimiento pleno respecto de los medios probatorios presentados en el proceso.

No olvidemos que uno de los principios probatorios más efectivos es el de comunidad de la prueba, mediante el cual los medios probatorios aportados no pertenecen en exclusiva a las partes, sino a los sujetos procesales que intervienen en el proceso civil. Así, rige la llamada regla prueba vs. contraprueba por la que el objetivo de la contienda procesal no solo es la defensa per se, sino el contragolpe, bien con las propias pruebas, o bien con las ofrecidas por el contrincante, de modo que estas le afecten en su contra.

Sin duda, esa práctica procesal no solo requiere de la pericia del operador procesal, sino también del conocimiento interno del medio probatorio que se va a requerir para contragolpear. De ahí que la práctica procesal aconseja conocer íntegramente no solo las propias pruebas, sino a su vez las del oponente, incluso más que él mismo. Se trata, pues, del empleo de dos componentes importantísimos en el arte de probar.

Pero ¿qué sucede cuando los medios aportados por las partes no le son suficientes al juez para realizar el ejercicio de valoración conjunta y poder encontrar la conexión de los medios probatorios aportados y actuados para la solución del caso? Cabe fijarse en que nuestra interrogante no se desarrolla sobre la idea aún usada de generar convicción en el juez, ya que el objeto del proceso dejó atrás la generación de convicción por su subjetividad relativa. El objeto del proceso es la solución del conflicto a través de una práctica científico-jurídico-procesal, en donde se relacionan la valoración de la prueba y el razonamiento sustantivo, por lo que el criterio del juez es sustituido por un máximo grado de aproximación de certeza.

Un conflicto no puede quedar en el limbo en el sentido de que al faltar un elemento sustancial de prueba el juez se abstiene de resolverlo. Al indicar elemento sustancial, nos referimos a la apariencia clara de la existencia de un medio de prueba que se encuentra en un estado de apariencia oculta, es decir que no ha podido ser propuesto por las partes, pero cuya existencia es percibida por el juez. Así, su tarea será el de deducirlo, encontrarlo y actuarlo.

La apariencia oculta del medio probatorio faltante no debe entenderse necesariamente como la intencionalidad de las partes de mantenerlo en dicho estado. Es factible que - por diversos factores - las partes no hayan sido capaces de encontrar ese elemento necesario para la solución del conflicto, por lo que no es propio suponer mala fe procesal. Esta, por su naturaleza, es evidente como consecuencia misma de su 
práctica al interior del proceso, pero no puede establecerse cuando no existe la capacidad probatoria del proponente.

En tales supuestos, surge la figura de la prueba de oficio, la cual ha sido objeto del surgimiento de distintas corrientes dentro del derecho procesal. Tanto es así que el proyecto del nuevo Código Procesal Civil considera la idea de la carga dinámica de la prueba, con lo cual parecería acercarnos a una forma metateórica de valoración probatoria, más allá del poder de la actuación de las partes y el riesgo de omnipresencia del juez, con todo lo que ello implica.

\section{HIPÓTESIS DE TRABAJO}

El presente trabajo no busca desarrollar los efectos procesales de la aplicación de la carga dinámica de la prueba, lo cual puede confundirse con el aporte de la prueba de oficio. El objetivo planteado es que, sobre la base de determinadas reflexiones, propongamos una base teórica que justifique suficientemente la actividad de impulso probatorio por parte del juez en el proceso civil, primordialmente.

La base sobre la cual parte este trabajo es la necesidad de plantear que, en el proceso civil, por su propia naturaleza, se ventilan conflictos jurídicos de distinta índole, a diferencia de la justicia penal o de cualquier otra especialidad, en donde la finalidad de los procesos es la búsqueda de la verdad material. Esa variedad de características de los procesos civiles gira en torno a la instrumentalización, es decir, en una secuencia de actos jurídicos plasmados en declaración de voluntad y dentro de negocios jurídicos complejos. Ello hace precisamente que los sujetos involucrados en aquellos actúen en el convencimiento de que el derecho les asiste, por lo que la finalidad de los procesos civiles de estas características será determinar cuál de los sujetos involucrados en el conflicto procedió conforme a derecho.

Desde esa perspectiva, la búsqueda de la verdad material como objeto del proceso se torna imprecisa. En consecuencia, la prueba resultante será aquella que recabe la mayor y mejor información sobre la forma como los sujetos procedieron durante el negocio jurídico que derivó en conflicto. Para tal efecto, se parte de un trabajo elaborado por un experimentado juez español en torno al carácter científico de la valoración probatoria para el debido razonamiento jurídico del juez, y que comprende también a la prueba de oficio.

El propósito de este trabajo es, a través del análisis del pensamiento de Perfecto Andrés lbáñez, proponer una justificación teórica de la incorporación al interior del proceso de los elementos necesarios para la comprobación de las premisas que sustenten la pretensión. Solo justificando la razonabilidad de la incorporación de la prueba de oficio, se podrá establecer su validez. 
Por lo tanto, este trabajo no contiene el tratamiento de las características formales y materiales de la prueba de oficio desarrolladas por la doctrina o la jurisprudencia, ni la norma procesal, ya que de ello se ha escrito abundantemente, tal como se puede extraer del X Pleno Casatorio Civil de la Corte Suprema de Justicia de la República. La propuesta radica, en todo caso, en presentar una justificación teórica que conlleve una fuerte dosis de razonamiento judicial que refuerce el uso de la prueba de oficio en el proceso civil.

\section{EL PENSAMIENTO DE PERFECTO ANDRÉS IBÁÑEZ COMO BASE DE TRABAJO}

A raíz de dos lecturas que hoy pueden considerarse clásicas en cuanto al deber de motivación y razonamiento de las resoluciones judiciales, surge un singular interés por relacionar el pensamiento del exjuez español Perfecto Andrés Ibáñez con la realidad más próxima posible en la práctica del derecho procesal. Ello, en cuanto a la valoración probatoria y la labor de encontrar la solución del conflicto jurídico alcanzando la certeza de los hechos invocados por las partes, y sin necesidad de tener que agotar vanos esfuerzos para buscar la realidad absoluta y total, que, a la postre, es de casi imposible realización en la práctica procesal.

Esas lecturas de Perfecto Andrés Ibáñez sobre las cuales intentaremos hacer una aproximación al presente trabajo son "Acerca de la motivación de los hechos en la sentencia penal" (1992) y "'Carpintería' de la sentencia penal (en materia de 'hechos')" (1998). El primer ensayo fue publicado en Doxa: Cuadernos de Filosofía del Derecho, 12, y el segundo en la Revista del Poder Judicial, 49, así como en Guía de trabajo para los textos de apoyo del curso "Valoración de la prueba en el proceso penal" de la Escuela de Capacitación Judicial. Ambos textos son auténticos precursores de la corriente que hoy sostiene el razonamiento jurídico como componente del deber constitucional de motivación de las resoluciones judiciales.

Aun cuando no es propósito de este trabajo ahondar en el contenido integral de dichas obras, sí es conveniente hacer una reseña breve de sus alcances para relacionarlas con la aproximación que intentamos hacer. Previamente, también es necesario precisar que la singularidad de ambos textos a la materia penal debe tenerse solo como referencia debido a la especialidad del exmagistrado, ya que todo lo desarrollado en ellas es común a la disciplina del razonamiento jurídico en la práctica judicial para la motivación de sus resoluciones y sentencias. Sin embargo, un aspecto que sí es necesario distinguir es que en el proceso civil, a diferencia del penal, el objetivo final de la prueba varía entre la verdad jurídica y la certeza, por cuanto, dadas las características de los conflictos civiles, la variada casuística fluye entre lo verdadero y lo cierto.

El primer texto ("Acerca de la motivación de los hechos en la sentencia penal") es un extenso trabajo de la filosofía del derecho relacionada con el juego de las premisas para determinar su validez a través de las prácticas deductivas e inductivas. El segundo 
texto podría considerarse como un apéndice del primero, no solo por su brevedad, sino por su complementariedad, al agregar algunas fórmulas sencillas de la práctica judicial para hacer más entendibles el esquema y la estructura del pensamiento del juez plasmado en una sentencia. Reiteramos que la singularidad de la especialidad penal solo se entiende por la especialidad del autor, ya que todos los componentes considerados en la integridad de los textos se advierten comunes en todas las demás ramas jurídicas sobre las cuales se desarrolla el derecho procesal, pero con la precisión indicada en párrafos anteriores.

Los nexos que unen el desarrollo integral de ambos textos con el presente trabajo se pueden encontrar en la redacción de los siguientes pensamientos:

Ese paso lo ha dado recientemente Ferrajoli. Este autor comparte el ya aludido clásico punto de vista de que el juez tiene que vérselas con una forma particular de verdad histórica, puesto que no está a su alcance la observación directa de las conductas objeto de enjuiciamiento. Pero, señala, la investigación judicial "no consiste solo en la recogida de datos y piezas de convicción, sino sobre todo en experimentar y producir nuevas fuentes de prueba", de manera que "lo que el juez experimenta no son los hechos delictivos objeto del juicio, sino sus pruebas". Ello, es decir, el intento de determinación de los hechos "probados" del pasado, a través del análisis de hechos "probatorios" del presente, confiere a la actividad las características de la inferencia inductiva. (Andrés Ibáñez, 1992, p. 273)

"La inducción parte de una hipótesis que parece sugestiva sin tener al inicio algún hecho en particular a la vista, aunque se tenga la sensación de la necesidad de hechos para sostener una teoría. La abducción busca una teoría. La inducción busca hechos. En la abducción la consideración de los hechos sugiere la hipótesis. En la inducción el estudio de la hipótesis sugiere los experimentos que hacen la luz sobre los hechos auténticos a los que la hipótesis se refiere". De esta cita de Peirce puede extraerse una conclusión elemental, que en ningún caso sería polémica: cualquiera que fuera la relación que llegue a establecerse entre inducción y abducción, ambas serían siempre formas de inferencia ajenas al modelo deductivo, es decir, sintéticas, cuyo resultado es innovador con respecto al contenido de las premisas y, por eso, siempre arriesgado. (Andrés lbáñez, 1992, p. 276)

Por otro lado, el proceso de adquisición de conocimiento sobre acciones de personas concretas que se desarrolla en el marco de procedimiento criminal responde al paradigma de la contradicción. 0 lo que es lo mismo, se realiza a través de una actividad controversial y dialógica, que los sujetos implicados en ella protagonizan, y ante un observador imparcial que es el que tiene que decidirla. (Andrés Ibáñez, 1998, p. 121)

[...] la pena ${ }^{1}$ tiene que haber sido precedida de una actividad de carácter cognoscitivo, de un estándar de calidad tal que permita tener como efectivamente producido

1 Para los efectos de este trabajo, léase: "el fallo". 
en la realidad lo que se afirma como tal en los hechos que se dicen probados. (Andrés lbáñez, 1998, p. 121)

Ese dato nuclear del diseño constitucional del juez y la jurisdicción se proyecta sobre la sentencia bajo la forma de una exigencia. Esta es que la dimensión de potestad de la decisión que contiene debe contar con la autoridad que solo puede darle la evidencia de tener como antecedente y fundamento una actividad de adquisición y valoración de los datos relevantes inspirada en criterios de racionalidad gnoseológica. (Andrés Ibáñez, 1998, p. 122)

Esta inflexión, no irrelevante, en el sentido y el destino del acto, no puede dejar de producir consecuencias en la propia morfología de este. En efecto, si tiene que explicarse - que es autoexplicarse - incluso para quienes no están en el conocimiento de que gozan los directamente implicados en el proceso, deberá incorporar los datos que sean precisos para que pueda ser así. (Andrés lbáñez, 1998, p. 122)

[...] la actividad probatoria se desarrolla a través de afirmaciones relativas a ellos (hechos), que se presentan en el acto de juicio de forma contradictoria, todas, siempre con la pretensión de ser tenidas por verdaderas y excluyentes. (Andrés lbáñez, 1998, p. 124)

[...] el objeto del proceso, tiene una consistente dimensión subjetiva, presente en la transmisión, en la recepción y, en general, en todo el curso de la elaboración de los datos. Dimensión de la que debe ser consciente el que juzga, para que su actuación esté presidida por una fuerte tensión a la objetividad. (Andrés Ibáñez, 1998, p. 125)

Para lo que aquí interesa, basta señalar que alcanzar el nivel ideal de rigor en la formulación de los enunciados que en la sentencia judicial constituyen los hechos probados. (Andrés Ibáñez, 1998, p. 128, nota a pie de página 25)

[...] la fase probatoria está siempre animada por esa tensión dialéctica entre lo particular y lo general. Y la valoración de la prueba como tal debe entenderse como la integración o mediación racional y consciente de ambos momentos. La valoración de la prueba solo puede ser, pues, valoración del rendimiento de cada medio de prueba en particular y del conjunto de estos. (Andrés lbáñez, 1998, p. 135)

[...] en el tránsito de una proposición singular en materia de hechos a otra del mismo género hay un salto lógico que no puede evitarse por la mediación de ley alguna. Se trata de un rasgo propio de la gnoseología inductiva, presente en el modus operandi de adquisición del conocimiento judicial en el proceso. [...] el acceso al conocimiento de este solo cabe mediante previa toma de conocimiento de otros datos que así mismo han de ser previamente probados. Es decir, a través de una cadena de inferencias. (Andrés Ibáñez, 1998, pp. 136-137)

Es importante destacar cómo el autor plasma todo su pensamiento en la aplicación de los complejos e intrincados factores variables de la lógica. Sin embargo, no siendo este un trabajo de lógica jurídica, sino de su aplicación y efectos en la práctica procesal, extraemos algunos elementos de análisis para proceder a su conexión con el propósito planteado, esto es, establecer: (i) cuál es la finalidad del proceso como consecuencia del 
contradictorio; (ii) cómo se produce la valoración conjunta de los medios probatorios, y (iii) la justificación - si ello es posible- de la actuación de la prueba de oficio; la gnoseología inductiva.

\section{LA FINALIDAD DEL PROCESO COMO CONSECUENCIA DEL CONTRADICTORIO. LA VERDAD MATERIAL O LA MÁXIMA APROXIMACIÓN DE CERTEZA}

En un proceso civil, se confrontan pretensiones y contrapretensiones. El conflicto intersubjetivo de intereses llevado al proceso para su solución jurisdiccional implica que esa confrontación de posiciones sustantivas propicie un amplio debate en un escenario judicial, en el cual las reglas preestablecidas determinan la forma en que los medios probatorios que sustenten las posiciones de las partes deben desarrollarse.

\section{El contradictorio en el proceso civil}

El proceso civil se rige, entre otros principios, por el de bilateralidad. Couture (1993, p. 183) precisa que, salvo situaciones excepcionales establecidas en la ley, toda petición o pretensión formulada por una de las partes en el proceso debe ser comunicada a la parte contraria para que esta pueda prestar a ella su consentimiento o formular su oposición.

Dado el conflicto intersubjetivo de intereses, la confrontación de posiciones llevada a la jurisdicción para su solución genera un lógico enfrentamiento de hechos y argumentos. Las partes acceden a la tutela procesal convencidas de que su posición es la correcta y, por tanto, exponen cada una su versión de los hechos, como mejor lo entienden.

El acceso a la tutela procesal solo se otorga cuando el juez, al calificar la demanda, encuentra fundamentalmente la existencia de una relación material y una apariencia de afectación de derechos que debe proteger o conceder. Ello se trasluce con el interés para obrar en su dimensión material, la cual precisamente deja ver que el conflicto posee base jurídica relevante. No cualquier pretensión desprovista de contenido jurídico de relevancia merece el acceso a la tutela procesal.

En consecuencia, ante tal exigencia de forma, desde la postulación del proceso el juez se enfrenta a posiciones claramente adversas, pero, sobre todo, entendiendo que las partes no claudicarán en ceder sus posiciones, salvo, claro, en las posibles formas especiales de conclusión de aquel. En ese escenario, la confrontación de sus posiciones al interior del proceso y a todo lo largo de él será, por tanto, tenaz.

Amato (2000) indica que como cada cual "tiene derecho a su propia visión de las cosas [...] sabe desde el principio que esta visión será puesta en duda [...]", de donde "la relacionalidad impone el riesgo de la relatividad y la relatividad garantiza la permanente apertura del intercambio relacional" (p. 185). Calamandrei (1973) precisa que el principio de contradicción debe ser siempre admitido a hacer valer ante el juez todas las razones 
de derecho y de hecho que puedan servir para demostrar la falta de fundamento del reclamo de la parte contraria. De modo que el impulso y la colaboración en la jurisdicción le llegan al órgano judicial desde dos partes; el juez no debe decir en virtud de una sola propuesta de providencia, sino que debe escoger entre dos propuestas, por lo general, antitéticas (pp. 238-239).

El contradictorio se presenta en situaciones normalmente comunes, a lo largo de todo el proceso. Salvo las formas especiales de conclusión, es la decisión judicial la que determinará cuál de las posiciones en controversia es la que más se ajusta a una solución en derecho. Aun así, al llegar al momento de la cosa juzgada como calidad, esta puede seguir siendo cuestionada hasta que, en todo caso, llegue al estado de autoridad y sea ejecutada irremediablemente.

El objeto principal del contradictorio se inicia con la postulación de las pretensiones de las partes. Cada etapa procesal experimenta un contradictorio específico conforme va evolucionando el proceso. No es una actividad fija y permanente. Se va desarrollando a través de un proceso dialéctico de argumentos. Por ello, es preciso asumir el real sentido de las etapas procesales.

\section{Las etapas del proceso}

La etapa probatoria no es la más importante del proceso. Todas las etapas procesales tienen el mismo grado de importancia.

La etapa postulatoria se caracteriza por que implica el inicio del debate procesal. Atendiendo a cómo se plantean las posiciones iniciales de la acción y contradicción, es el mejor momento para establecer las bases de una estrategia procesal que tenga por finalidad el éxito, que se traduce en una sentencia favorable que reconozca el derecho pretendido. Por tanto, una demanda imprecisa o la omisión de aportar un medio probatorio necesario para fortalecer su posición genera una clara desventaja en la posición del actor. Igual sucede con la contestación de la demanda: una mala defensa inicial es difícil de revertir posteriormente, aun cuando se tenga la razón aparente.

Monroy Gálvez (1992) precisa que es aquella en la que los contendientes presentan al órgano jurisdiccional los temas que van a ser materia de argumentación, prueba y persuasión durante el proceso, sea porque se quiere el amparo de la pretensión o porque se busca su rechazo a través de la defensa (p. 33). En esta etapa, no solo se fijarán inicialmente las pretensiones bajo el planteamiento de premisas, sino que lo importante es que el juez fijará la controversia de manera precisa. Si el proceso no es adecuadamente postulado, o si las pretensiones se desvían por error en la propuesta de las premisas, no cumplirá su finalidad debida.

La etapa decisoria a través de la sentencia implica la conclusión de la primera parte del proceso, cuando este es objeto de recursos impugnatorios. Por tanto, la solución del 
conflicto mediante una sentencia debidamente motivada es la muestra de la garantía que deviene del correcto razonamiento judicial y de la argumentación desarrollada a través de la valoración de los medios probatorios, y la aplicación exacta del derecho contenido.

La motivación de las resoluciones judiciales ha llegado a la jerarquía de derecho constitucional, no solo por estar normada en el inciso 5) del artículo 139 de la Constitución, sino porque es derecho de todo ciudadano recibir una decisión judicial sobre la base del razonamiento argumentado, y es obligación de todo juez cumplirla.

La etapa revisora, mediante la apelación de la sentencia, habilita la segunda parte del proceso (el segundo tiempo). En esta etapa, el contradictorio sigue vigente y, por tanto, la actividad probatoria continuará abierta si es que se dan las condiciones normativas para ello. Además, posibilita corregir los posibles errores que puedan estar contenidos en la sentencia.

La etapa de casación es una de carácter extraordinario, porque no es propiamente una instancia. El contradictorio culmina en la segunda parte (segunda instancia) y la etapa de casación solo se habilita cuando los presupuestos de infracción normativa contengan una clara precisión e identificación.

Dejamos la etapa probatoria al final de este esquema, por cuanto se relaciona con el presente trabajo. En apariencia, algún sector puede considerar que es la parte más importante del proceso, porque en ella se actúan los medios probatorios y, dependiendo de la forma en que se haga, puede ganarse el caso. Sin embargo, teniendo el mismo grado de importancia de las otras etapas del proceso, no obstante, es la más activa. Es decir, es el momento en que el contradictorio se desarrolla con mayor intensidad a través de la actuación de los medios probatorios.

\section{El objeto de la prueba. ¿La verdad o la máxima aproximación de certeza?}

Pero ¿cuál es, entonces, la finalidad de probar?

En la misma línea de Andrés Ibáñez, Ferrajoli y otros autores, consideramos que el juez se enfrenta a una realidad histórica que debe descubrir. Esa realidad histórica tiene dos versiones, una por cada parte del proceso. Por tanto, el juez no accede directamente a los hechos, sino a proposiciones relativas a los hechos.

Es aquí donde aparece el primer elemento que percuta la actividad probatoria: las premisas. Las premisas son proposiciones que se afirman; pueden ser verdaderas o falsas y permiten determinar una conclusión. Pero, en el ámbito procesal, no cualquier premisa es válida para someterla a comprobación a través de los medios probatorios. Solo serán sometidas a la actividad de probar aquellas que han pasado el filtro de calificación como puntos controvertidos. 
Así pues, la relación que existe entre las premisas que forman parte de las pretensiones y contrapretensiones, y los medios de prueba es la fijación de los puntos controvertidos. Ya en trabajos anteriores hemos desarrollado la necesidad de que el juez fije del mejor modo los puntos controvertidos. Ello obedece fundamentalmente a la necesidad de encontrar la mejor fórmula para identificar el caso concreto (Salas Villalobos, 2014).

Como se ha mencionado en el segundo acápite, el proceso penal y el proceso civil se distinguen fundamentalmente por las características de ambas especialidades. Mientras que en el derecho penal el objeto central del proceso es la determinación de la comisión de una conducta considerada como ilícita, debidamente tipificada, en el proceso civil se debaten intereses intersubjetivos opuestos; es decir, trata sobre conflictos entre dos sujetos de derecho por la relación jurídica que los une. Al fenómeno de coexistencia de una pretensión y de una resistencia acerca de un mismo bien en el plano de la realidad social, Alvarado Velloso (2016) lo denomina conflicto intersubjetivo de intereses.

En el proceso penal, por ende, la finalidad se acerca más a determinar la verdad material en cuanto a la realidad de los hechos que tipifican las conductas penales. En el proceso civil, en cambio, se contraponen dos historias de los hechos. Esta contraposición no es necesariamente intencional, sino que, por las características de las distintas modalidades de las relaciones jurídicas entre los sujetos - las cuales, a diferencia del derecho penal, no están tipificadas-, estos interpretan los hechos de distinta forma, de manera que esa "forma" de ver distintos los hechos hace que se produzca el conflicto.

Esta singular característica del proceso civil nos lleva a repasar lo propuesto por Taruffo (2013) respecto de la verdad dentro del proceso. El recientemente desaparecido tratadista italiano refiere que, en el mundo procesal, se trata la distinción de la verdad absoluta y la verdad relativa. Para el eminente jurista, no es correcto afirmar que la verdad no existe en el proceso, a pesar de que, dentro de este, hay límites que impiden su detección. Por eso, asigna el nombre de verifobia a quienes consideran que la verdad absoluta por ser demostrada es un imposible real y que concluyen, por lo tanto, que en el proceso no se puede descubrir ninguna verdad absoluta.

Así, refiere el maestro, que en el modelo adversarial la única y exclusiva finalidad es resolver la controversia a través de la victoria de uno de los contendientes, y el contenido de la decisión que cierra el proceso es solo aquel que registra la victoria de una parte y la derrota de otra. A su entender, este modelo no está estructuralmente orientado hacia la determinación de la verdad (Taruffo, 2013, p. 242).

Cita también al modelo ritual, al que define como una suerte de espectáculo teatral, en donde la decisión final queda legitimada por el procedimiento, no por lo que dice. En ese aspecto, la verdad que deriva de la determinación de los hechos es irrelevante. 
Precisa, entonces, que existen distintos tipos de verdad que se pueden presentar, de acuerdo con los tipos de procesos. Entendemos que ello es así, en cuanto será la casuística la que, finalmente, determine esos tipos de procesos en los que la verdad pueda concurrir. Por ejemplo, en los procesos de ejecución, el estado de mora es sin duda una verdad; o, en los procesos de declaración de paternidad, la prueba científica del ADN establecerá la verdad absoluta respecto de la filiación paterna.

Taruffo (2013) concluye que, desde el punto de vista procesal, la norma viene correctamente aplicada en el caso concreto, sí y solo sí se ha determinado la verdad de una proposición (o un conjunto de proposiciones) que describe el hecho. En otras palabras, la determinación de la verdad del hecho se califica como jurídicamente relevante según la norma que viene aplicada. Así pues, ninguna norma es aplicada correctamente si los hechos a los cuales se refiere han sido determinados de manera errónea o falsa.

Nuestra postura apunta a aquellos casos en los que ambas partes sostienen sus premisas como verdaderas, y en las que el nivel de definición del conflicto es incierto. Es en estos casos en los que sostenemos que la verdad como ideal del proceso es una meta ambigua.

Ese fin de descubrir la verdad absoluta constituye el ideal al que las partes del proceso quieren llegar, y el juez apreciará quién lo hará. Pero, como se ha referido, las características del proceso civil hacen que esa finalidad sea prácticamente imposible e irrealizable, por lo cual, en todo caso, el juez verificará cuál de las dos partes, a través de la actuación de los medios probatorios, se aproximó lo más cerca posible a la meta, al ideal. Esta es la "máxima aproximación de certeza".

Delgado Suárez (s. f.) indica que lo verosímil es lo más próximo a la representación de una realidad percibida. Además, dado que el juez, de acuerdo con Comanducci, no es un historiador para buscar lo que realmente ocurrió - con cargo a jamás encontrar tal verdad-, el ámbito de actuación probatoria recaerá en lo que con mayor probabilidad haya ocurrido según lo probado.

Desde una posición pragmática, nos adherimos a esta tendencia. El proceso implica el consumo de energías en cada actuación procesal, por lo que no es propio para la misma salud del proceso agotar más energías que las debidas en algo que puede ser imposible de alcanzar. Una buena estrategia procesal ayuda a eso.

Por lo tanto, y como lo refiere Taruffo (2013), existen distintos tipos de verdad que concurren al proceso, pero, en aquellos casos en los que el conflicto se aprecia especialmente complejo y debatible, no está de más alcanzar el máximo grado de aproximación de certeza, no para descubrir la verdad, sino para darle al conflicto una solución adecuada, justa. 


\section{La hipótesis de los casos}

Siguiendo con nuestro análisis del pensamiento de Perfecto Andrés lbáñez, la forma de contraponer las premisas de las partes es a través de la postulación de sus hipótesis. Esto es, planteando objetivamente las premisas de sus pretensiones y desarrollando la actuación de sus medios probatorios para la comprobación de aquellas. El resultado final implica que solo una de las hipótesis será verdadera, en términos de lógica procesal, ya que, como hemos referido, el objetivo es lograr la máxima aproximación de certeza.

Una hipótesis es la suposición de algo que podría ser posible o no. Es una idea o supuesto a partir del cual surge la pregunta del porqué de una cosa, sea un fenómeno, un hecho o un proceso. Como tal, la hipótesis permite dar inicio al proceso de razonamiento mediante el cual se accede a determinados conocimientos. Rabbi-Baldi Cabanillas destaca la opinión de Amato (2000), quien ha escrito que "toda la experiencia procesal se justifica en virtud de una hipótesis que hay que demostrar" en el contexto de un encuentro entre partes guiadas por un tercero imparcial.

El elemento principal de la hipótesis es la identificación de sus premisas, aquellas que se quieren demostrar como verdaderas. Las premisas son señales, indicios o especies por donde se infiere una cosa, o se viene en conocimiento de ella. Constituyen la base, supuesto o punto de partida para un razonamiento (Ausín y Peña, 2011).

Las premisas son las afirmaciones que apoyan o sustentan la conclusión, pero habrá que determinar cuál es el nexo que permite esa relación de consecuencia y cuán fuerte es dicha conexión (Ausín y Peña, 2011). Tales nexos de conexión son las pruebas que sustentan el valor de la premisa y que, finalmente, llevarán a una conclusión que se quería demostrar. Dado que un teorema comienza siempre con una proposición que posteriormente hay que demostrar, al final se demuestra ciertamente aquello de lo que se partió.

Dentro de la lógica, esa conclusión o demostración de la hipótesis se tiene por verdadera, con lo cual se define el conflicto. Es precisamente lo que Taruffo (2013) define como la verdad procesal referida anteriormente, esto es, "la norma viene correctamente aplicada en el caso concreto, sí y solo sí se ha determinado la verdad de una proposición (o un conjunto de proposiciones) que describe el hecho" (p. 243).

Pero, en el terreno de los hechos inciertos y controvertidos, y sobre los cuales se han activado los medios probatorios, esa conclusión es cierta. Reiteramos: la certeza a la que se arribó es la fórmula ideal de solución de un conflicto civil que se caracteriza por su notoria incertidumbre. Al menos, en estos tipos de procesos. 


\section{LA VALORACIÓN DE LOS MEDIOS PROBATORIOS}

La evolución del derecho procesal bajo el imperio del sistema publicístico ha implicado no solo la transformación del proceso, sino la precisión de los roles que les compete a los sujetos procesales y a la actuación de los medios probatorios para la demostración de sus premisas.

En el derecho procesal moderno, ya no podemos hablar de la concurrencia de varias pruebas para demostrar un hecho. En una concepción más amplia, la prueba es el resultado final de la apreciación de otros elementos que concurren de manera conjunta. Devis Echandía (2000) define la prueba "como el conjunto de motivos o razones, que de los medios aportados se deducen y que nos suministran el conocimiento de los hechos, para los fines del proceso" (pp. 20-21). Por tanto, esos medios aportados a los que se refiere Devis Echandía (2000) son reconocidos como los medios probatorios propiamente dichos, de los cuales se debe extraer un conocimiento determinado para proceder a la llamada valoración conjunta.

\section{Los medios probatorios del sistema privatístico}

La vieja clasificación del valor de los medios probatorios - que distingue prueba plena, prueba privilegiada y prueba simple- no solo ha quedado en desuso, sino que, para los efectos del proceso, y para garantizar un proceso justo, todos los medios probatorios quedan homologados. De esta manera, parten de valores individuales e incidirán en la conclusión dependiendo del "conocimiento" que cada uno posea y sea posible vincularlo con los demás.

En el antiguo sistema procesal, el objeto del proceso era alcanzar la "verdad legal", es decir, aquella que fluía de la ley procesal. Con tal fin, la ley establecía el valor que los medios probatorios poseían, y así era usual que quien sumaba mayor puntaje por este valor legal ganase el caso. La verdad estaba en la ley.

Bajo el imperio de la prueba tasada en la ley, la llamada prueba plena era aquella que por su solo mérito poseía tal valor que per se era suficiente para generar "convicción" en el juez para resolver el caso. "A confesión de parte, relevo de prueba", rezaba el viejo adagio. Sin embargo, hay que distinguir la casuística civil, en la que, en determinados casos, concurre la prueba científica que, por su solo mérito, puede acreditar un hecho; los casos de filiación con ADN son un claro ejemplo. Pero solo en esos casos la prueba plena puede considerarse como válida. Necesita, por ende, el refuerzo del saber científico para adquirir esa categoría excepcional. No obstante, en los procesos civiles eminentemente contradictorios, en los que se contraponen dos hipótesis que pretenden ser fuertes, queda prácticamente descartada la valoración plena de un solo medio probatorio. 
La llamada confesión dejó de ser una prueba plena para convertirse en declaración de parte, y esto, precisamente, porque dejó de tener un valor pleno. La fórmula legal del Código de Procedimientos Civiles para otorgar este valor extraordinario a la confesión era "La confesión surte efectos contra quien la presta". De esta manera, en un pliego interrogatorio bajo la absolución de posiciones sobre el fondo de la controversia, como “Diga cómo es verdad que...", quien respondía "sí es verdad" tenía pocas posibilidades de ganar el caso.

Otra clasificación tradicional era la prueba privilegiada. Era la que, sin llegar a la categoría de ser plena, no obstante, poseía un grado de valor alto, el cual difícilmente se podía cuestionar. Dentro de esta categoría encontramos los antes llamados instrumentos públicos, es decir, todo documento expedido por la autoridad administrativa o funcionario público en ejercicio de sus funciones. Respecto de la veracidad de los documentos públicos, ella se regía por un principio de verdad material, que solo podía ser cuestionado mediante una declaración judicial de falsedad. La diferencia respecto de la tacha de los documentos de nuestro actual sistema judicial es la misma que entonces.

Otra prueba en este rubro era la inspección ocular, hoy llamada inspección judicial. Era la prueba del juez, y, por tanto, era imposible restar apreciación valorativa a la prueba del juez.

La pericia practicada por expertos en ciencias o artes en las cuales los profesionales en el derecho carecían - y carecen- de mayores conocimientos era, igualmente, una prueba de importancia mayúscula. El cuestionamiento al contenido técnico de una pericia era prácticamente una labor imposible. En este aspecto, es relevante la diferencia con el sistema procesal penal, en el que un dictamen pericial es sometido a un "debate pericial", donde el perito de parte puede, en efecto, debatir con el oficial. Auténtica diferencia del sistema procesal civil, en el que se exigía una simple "ratificación".

Por último, las pruebas simples eran las que menor valor poseían. En esta categoría estaban los documentos privados y las declaraciones testimoniales. Eran solo referenciales. Los primeros, para que puedan tener algún grado de valor, previamente debían ser reconocidos en contenido y firma. Si solo se reconocía la firma, mas no el contenido, era indudable que el documento carecería de valor probatorio. En cuanto a los testigos, estos mantenían igualmente una referencia relativa, ya que, en todo caso, su declaración quedaba a cargo del juez bajo el estándar de las reglas de la "sana crítica".

\section{Los medios probatorios en el sistema publicístico}

La clasificación de los medios probatorios según su valor, como se ha referido anteriormente, ha quedado en desuso. Todos los medios probatorios ahora parten de un mismo valor inicial -digamos, de un valor "cero"-y será en el transcurso del contradictorio, 
a través de la oralidad en la etapa probatoria, cuando comenzarán a adquirir mayor o menor valor.

La graduación de prueba plena, privilegiada y simple queda, entonces, descartada, aun cuando algún sector la sigue considerando importante. Sobre este punto, y apartándonos de un pensamiento absolutista, en todo caso, se aprecia la concurrencia de la prueba relevante, es decir, aquella que por su contenido es de un valor trascendentalmente fundamental. Este tipo de pruebas hará más fácil la labor de la valoración conjunta con los demás medios probatorios concurrentes.

La diferencia de la prueba confesional con la declarativa de parte varía sustancialmente en su formalidad y contenido. A la vieja práctica de la absolución de posiciones a través de un pliego interrogatorio, se incorpora la técnica del interrogatorio libre. Existen muchas formas de practicar esta técnica, pero todas ellas se orientan hacia un mismo objetivo: la contradicción del declarante.

En este punto, sin duda la oralidad se convierte en un mecanismo procesal trascendental. No solo el intercambio entre el emisor y el receptor, sino el lenguaje gestual. Ahora bien, indudablemente que quien declara con la verdad de los hechos difícilmente podrá entrar en contradicción manifiesta. Sin duda, la prueba declarativa de parte dejó de ser prueba plena. El mismo criterio se aplica a la declaración testimonial.

En cuanto a la prueba privilegiada, esta ha experimentado una suerte de "fusión" con la prueba simple. La antes llamada prueba instrumental se rige en la actualidad por la formalidad de la prueba documental, de modo que todos los "documentos", sean públicos o privados, poseen el mismo valor, bajo el principio también de la verdad material. De este modo, solo pierden su valor natural si son efectivamente detectados como falsos a través del remedio procesal de la tacha. De este modo, el reconocimiento de un documento o su carácter público no incidirá en el valor que emane del documento.

Un aporte sustancial en este punto es la definición de lo que se considera documento. La fórmula normativa del artículo 234 del Código Procesal Civil otorga calidad de tal a

los escritos públicos o privados, los impresos, fotocopias, facsímil o fax, planos, cuadros, dibujos, fotografías, radiografías, cintas cinematográficas, microformas tanto en la modalidad de microfilm como en la modalidad de soportes informáticos, y otras reproducciones de audio o video, la telemática en general y demás objetos que recojan, contengan o representen algún hecho, o una actividad humana o su resultado.

Los medios informáticos de audio y video referidos no eran considerados propiamente como prueba en el sistema privatístico. En todo caso, eran referenciales, pues estaban sujetos a un análisis técnico de autenticidad. 
Con la variación en el sistema publicístico, estos medios deben ser comparados con los otros medios aportados para establecer una correlación de razonable información que acredite la certeza de los hechos. Si bien la evolución tecnológica incide en la naturaleza de estos medios audiovisuales, no obstante, por no tener un valor absoluto, el contenido de su información relevante, al ser comparado con el resto del material probatorio, conducirá a la determinación de lo cierto. No se requerirá, pues, necesariamente un análisis técnico de autenticidad, salvo que el caso concreto lo requiera.

La prueba pericial ha dejado de ser una prueba incontrovertible para ser sujeta a demostración cierta por parte del perito. La ratificación de sus conclusiones técnicas o científicas no será suficiente para graduar el valor. La jurisprudencia nacional, mediante el IX Pleno Jurisdiccional de las Salas Penales Permanente y Transitoria, Acuerdo Plenario N. ${ }^{\circ} 04-2015 / \mathrm{ClJ}-116$, que recoge la posición de la doctrina (Miranda Estrampes, 2012, pp. 142-143), ha establecido ciertos parámetros de contenido de la prueba pericial:

a. La controlabilidad y falsabilidad de la teoría científica, o de la técnica en que se fundamenta la prueba, lo que implica que la teoría haya sido probada de forma empírica, no solo dentro de un laboratorio.

b. El porcentaje de error conocido o potencial, así como el cumplimiento de los estándares correspondientes a la prueba empleada.

c. La publicación en revistas sometidas al control de otros expertos de la teoría o la técnica en cuestión, lo que permite su control y revisión por otros expertos.

d. La existencia de un consenso general de la comunidad científica interesada.

Es, pues, tarea de la parte contraria valerse de la asesoría técnica o científica especializada, no solo para verificar el contenido de tales parámetros, sino para contradecir las conclusiones contrarias que se van a debatir.

Por último, en cuanto a la prueba de la inspección judicial, esta, a pesar de ser actuada por el juez, dejó de ser su prueba, y también debe ser sometida al contradictorio, en virtud del principio de comunidad o adquisición. Por este principio, la prueba deja de pertenecer a quien la aporta y pertenece al proceso mismo, de manera que cualquiera de los sujetos procesales podrá hacer uso de ella a través del ejercicio del contradictorio.

El hecho de que sea el juez el que practique directamente una inspección judicial, per se, no le da un mayor valor que los demás medios de prueba. Además de poder estar sujeto al contradictorio, este medio probatorio debe ser pulcramente actuado por el juez. Existen ciertos parámetros mínimos indispensables para que una inspección judicial pueda producir conocimientos suficientes para ser valorada.

Estos parámetros pueden referirse a requisitos de existencia y de validez (Devis Echandía, 2002). Los primeros son estos: que sea practicada por el juez en el ejercicio 
del cargo, lo que conlleva la formalidad y solemnidad del acto; que se trate sobre existencias, lo que descarta las suposiciones o deducciones; y que se actúe en un único y primer momento, lo que impide al juez hacer una "visita previa". En cuanto a los requisitos de validez, son que no exista prohibición legal, que se respete la publicidad para garantizar a las partes el ejercicio del contradictorio y que se proscriba la rectificación o retractación del juez. Por ello, una inspección judicial que quiebre los requisitos de existencia y de validez implica una deficiente actuación probatoria, de la cual la parte interesada puede obtener variables ventajas.

\section{El contenido de los medios probatorios}

$\mathrm{Si}$, como hasta acá se ha postulado, los medios probatorios parten todos de un valor "cero", ¿cómo es posible precisar sobre ellos un valor determinado para ser posteriormente vinculado con los demás? En otras palabras, ¿cómo se establece el valor del medio probatorio? La respuesta es conociendo su contenido.

Sobre el particular, Andrés Ibáñez (1998) indica refiriéndose al hecho: “[...] el acceso al conocimiento de este solo cabe mediante previa toma de conocimiento de otros datos que así mismo han de ser previamente probados. Es decir, a través de una cadena de inferencias [...]" (p. 137). Entendemos, en consecuencia, que cada medio probatorio aportado al proceso contiene determinada información que guarda relación con los hechos propuestos. Por consiguiente, mediante el contradictorio, la meta es "descubrir" toda la información contenida en el medio probatorio para poder elegir los datos que sean más relevantes en relación con el hecho propuesto.

Por lo tanto, no todos los datos de información contenidos en el medio probatorio serán sometidos a un proceso de valoración conjunta. Se escogerán solo aquellos más relevantes, útiles e idóneos que tengan estrecha relación con los hechos propuestos. Ese núcleo de información útil es el que le dará un valor significativo, que deberá, a su vez, ser relacionado con los demás medios probatorios. Se establece, entonces, como refiere Perfecto lbáñez (1998), una inferencia.

Según Vega (2011), el término inferencia se usa en diversos contextos: (i) en un contexto psicológico, para denotar la acción o el resultado de inferir algo a partir de algo; (ii) en un contexto epistemológico o metodológico, para indicar un proceso discursivo de transición o cambio de estados de información, creencia o conocimiento; y (iii), en un contexto lógico, para referirse a una relación semántica entre proposiciones (p. 298).

Para la práctica procesal, consideramos más acertada la segunda definición. Al respecto, Vega (2011) precisa que, en un uso más específico y en contextos relacionados con nuestras vías y formas de conocer, el término se refiere más bien al proceso discursivo por el que alguien pasa una información, una creencia o un conocimiento, a otra creencia o a otro presunto conocimiento, por ejemplo, "que, a juzgar por todos los 
indicios, el culpable ha sido el mayordomo". En ese sentido, en el ámbito del proceso, y para los efectos de extraer el verdadero valor de los datos contenidos en el medio probatorio examinado (actuado), aquellos que han logrado aprobar la selección necesaria formarán una inferencia.

\section{Forma de valorar conjuntamente los medios probatorios}

Devis Echandía (1981, p. 117) precisa que, por el principio de unidad de la prueba, los medios aportados al proceso forman una unidad. Como tal deben ser examinados y valorados por el juzgador en forma conjunta, confrontando uno a uno todos los diversos medios de prueba, puntualizando su concordancia o discordancia, para finalmente concluir sobre el convencimiento que a partir de ellos se forme.

Similar concepto plantean Peyrano y Chiappini (1985, p. 125), al indicar que el material probatorio ha de ser apreciado en su conjunto mediante la concordancia o discordancia que ofrezcan los diversos elementos de convicción arrimados a los autos, única manera de crear la certeza moral necesaria para dictar el pronunciamiento judicial definitivo. Se trata, en consecuencia, de vincular los conocimientos extraídos individualmente de cada medio probatorio y poder relacionarlos de manera conjunta, de modo que, como resultado de dicha actividad, se arribe a una conclusión lógica y cierta.

Podría afirmarse que este tipo de valoración conjunta implica el desarrollo de una metodología de análisis comparativo de todos los medios probatorios vinculados, entendiéndose que lo que se vincula son los datos útiles de la información contenida en aquellos. Este análisis comparativo implica que el juez conozca a cabalidad el resultado de cada inferencia que se produzca de manera individual y, posteriormente, compare cuáles son las coincidencias con las demás inferencias adquiridas. Esta actividad logrará formar la cadena de inferencias válidas (que refiere Perfecto Andrés lbáñez) para poder establecer la certeza requerida, obviamente, sin prescindir del razonamiento jurídico necesario.

No existe, pues, contradicción entre el método de valoración conjunta de los medios probatorios y el principio de la unidad de la prueba. El primero, como se ha precisado, aplica una metodología de valoración individual (inferencia) para luego proceder a la comparación entre los datos relevantes de cada medio probatorio. Unida esta cadena de conocimientos (inferencias), la conclusión es una y solo una. Es en este momento cuando la prueba se consolida en una unidad de conocimiento concluyente.

\section{LA GNOSEOLOGÍA INDUCTIVA Y LA PRUEBA DE OFICIO}

Recordemos el pensamiento de Andrés Ibáñez (1998):

[...] en el tránsito de una proposición singular en materia de hechos a otra del mismo género hay un salto lógico que no puede evitarse por la mediación de 
ley alguna. Se trata de un rasgo propio de la gnoseología inductiva, presente en el modus operandi de adquisición del conocimiento judicial en el proceso. [...] el acceso al conocimiento de este solo cabe mediante previa toma de conocimiento de otros datos que así mismo han de ser previamente probados. Es decir, a través de una cadena de inferencias. (pp. 136-137)

El propósito de este trabajo no es recurrir a las fórmulas normativas, jurisprudenciales o doctrinarias que tratan la prueba de oficio. Es claro que dichas fuentes son extensas en describir las condiciones por las cuales los jueces ejercen este deber-poder o facultad para aportar al proceso una prueba de oficio.

La intención, en todo caso, es formular un sustento teórico diferenciado, de manera que se pueda justificar el empleo de esa facultad exclusiva del juez. Vale decir, desde el punto de vista de la valoración probatoria, poder determinar cuándo se hace necesario el impulso probatorio por parte del juez, quien no es parte, pero sí sujeto procesal y, como tal, desarrolla un rol activo dentro del proceso. No solo es director, también es actor, porque actúa medios probatorios, en este caso, la prueba de oficio. Por lo tanto, nos apartamos del análisis - ya abundante- de los elementos característicos de orden normativo, jurisprudencial y doctrinario, para alcanzar esa justificación teórica.

\section{De la generación del conocimiento (gnoseología) por inferencias}

De acuerdo con lo anteriormente tratado, tenemos que los medios probatorios actuados generan una inferencia, es decir, un conocimiento determinado sobre el cual el juez va a realizar una valoración conjunta a través de la interrelación entre ellos. Todo lo que vincule y tenga una estrecha relación con la inferencia generada en cada medio de prueba será unido para crear una cadena de inferencias, una cadena de conocimientos.

La formación de esta cadena de inferencias, como resultado de la actuación probatoria ejercida por las partes y dirigida por el juez, es la consecuencia natural del contradictorio al interior del proceso. Sin embargo, llegar a este punto procesal no es una acción automática ni protocolar de las partes, sino que implica el logro del cometido de demostrar la causa petendi, entendida esta como la conformada por supuestos de hecho a partir de los cuales se podrá derivar lógicamente la consecuencia jurídica solicitada (Apolín Meza, 2004, p. 37).

Llegar a este momento del proceso, respecto de la intensidad de la actuación probatoria, no solo comprende el simple hecho de demostrar. El contradictorio requiere de la acción directa e inmediata, de estrategias procesales legales y leales para la contienda prueba vs. contraprueba, es decir, utilizar tanto los medios probatorios de parte como los de la contraparte a favor.

Tal es la esencia del principio de comunidad de la prueba. Los medios de prueba no pertenecen a la parte que los aporta. Pertenecen al proceso mismo y, por lo tanto, quien 
tiene "mejor conocimiento" del contenido de ellos podrá, sin duda, extraer toda la utilidad requerida a su favor. En este ámbito se encuentra incluso la prueba del juez (inspección judicial), ya que una mala inspección puede ser contradicha por las partes, si se produce una infracción a los requisitos de existencia y de validez, como se ha referido antes.

Esta actividad de prueba vs. contraprueba conlleva también "destruir" la prueba del contrario. Restarle toda su esencia o la máxima que sea posible, "inutilizarla". Atacar al contrario y contraatacarlo con sus propias armas. En pocas palabras, dejarlo indefenso, que no es lo mismo que vulnerar su derecho de defensa, pues, al participar en la actividad probatoria precisamente ejerciendo tal derecho, simplemente "se quedó" sin defensa.

Si bien este ejercicio se realiza con el contradictorio, no obstante, existen también otras herramientas válidas y legítimas para lograr este cometido, como son los remedios procesales de la oposición y la tacha. Estos son los más eficaces y prácticamente están diseñados para "atacar" la utilidad de los medios de prueba.

Al final, y superados todos los escollos que ha implicado el arte de probar, como se ha indicado, el objetivo es formar una cadena de inferencias para que el juez pueda desarrollar la valoración conjunta de los medios probatorios, y proceda al ejercicio de razonabilidad para la argumentación, motivación y justificación de su decisión.

Sin embargo, ¿qué sucede en aquellos casos en que esa cadena no llega a cerrarse por falta de la concurrencia de una inferencia que no ha podido ser aportada por las partes? Es decir, a la cadena de conocimientos le falta un eslabón para poder vincularlos y arribar a una conclusión.

El conflicto debe y tiene que ser resuelto por el juez. No puede abstenerse de resolver porque ninguna de las dos partes estuvo en la capacidad de impulsar los medios probatorios necesarios para resolver el conflicto.

En el quehacer jurídico, son variadas las causas por las que las partes del proceso no aportan medios probatorios completos para confirmar sus premisas. Por ejemplo, por no haber tenido acceso a ellas, por desconocimiento de su fuente, por deficiente estrategia procesal o, simplemente, por ocultarlas.

En cualquier circunstancia, el juez debe advertir la necesaria incorporación del medio probatorio faltante. No hacerlo le impide resolver el conflicto de manera adecuada. Puede que, en efecto, no lo incorpore, pero de esa manera el conflicto no solo no será resuelto adecuadamente, sino que puede agravarse aún más por una mala decisión. Es entonces cuando la incorporación de esa inferencia no concursada cobra especial relevancia. No solo se hace necesaria, sino que se torna indispensable. Es la incorporación de la llamada prueba de oficio. 


\section{De la inducción del conocimiento. La prueba de oficio}

Según Vega (2011, p. 294), se considera inductiva cualquier inferencia que cumpla estas dos condiciones: (i) no ser deductiva y (ii) ser ampliativa, en el sentido de facilitar el acceso a, o acreditar la adquisición de, nuevos conocimientos materiales o sustantivos. Del mismo modo, según Corcoran (2011), la deducción es el proceso para determinar que una conclusión se sigue de ciertas premisas, siendo una consecuencia lógica de ellas. Es la hipótesis comprobada.

Se trata, pues, de dos conceptos opuestos. La deducción es la consecuencia lógica de las premisas demostradas como ciertas. En el plano procesal, ello implica que la cadena de inferencias (conocimientos) extraída de la actuación de los medios probatorios ha producido un resultado lógico. La cadena no se interrumpió. Los conocimientos están completos, de modo que el juez procede al análisis comparativo y luego a la valoración conjunta que le permita acceder al razonamiento argumentativo y dar solución al conflicto.

Por otro lado, y ese es el motivo de este trabajo, cuando esa deducción no se puede dar porque está incompleta la cadena de inferencias, es el momento en que se debe proceder al proceso de inducción. La inferencia no puede ser deductiva.

Este proceso tiene por finalidad incorporar un conocimiento nuevo y necesario, a la vez que indispensable, para completar debidamente la cadena de inferencias. En esencia, es el eslabón que falta para completar los conocimientos necesarios y arribar a lo cierto.

Ese conocimiento inducido es, en consecuencia, la prueba de oficio. A partir de esta determinación teórica, los requisitos o presupuestos procesales para aportar el medio probatorio por el juez y actuarlo son estos: recién se presentan y se hacen exigibles. En consecuencia, no es que el juez recurra primero a los presupuestos para aportar la prueba de oficio y después la justifique, sino a la inversa. Primero, debe justificar la necesidad de incorporar un conocimiento nuevo para poder arribar a una inferencia.

Dicha justificación, en nuestro concepto, implica argumentar por qué es que no puede proceder al análisis comparativo de los medios probatorios para su valoración conjunta. Indicar cuál es el elemento cognoscitivo faltante para completar la cadena de inferencias, es decir, qué conocimiento necesita descubrir. Como hemos mencionado, un medio probatorio posee mucha información de contenido, pero no todo el contenido estará sujeto a análisis. Por ello, la precisión del contenido que se requiere debe ser justificada por el juez. Por último, en este proceso de descubrimiento cognoscitivo, deberá identificar de manera puntual, ahora sí, cuál es el elemento material que requiere. Este será la prueba de oficio.

En consecuencia, tratando de definir el concepto de gnoseología inductiva, esta será la incorporación de un conocimiento nuevo e indispensable para completar la cadena de 
inferencias. Este permitirá al juez hacer un análisis comparativo de los medios probatorios actuados, realizar posteriormente el razonamiento judicial con la debida motivación y argumentación jurídica, y resolver el conflicto arribando a la máxima aproximación de certeza, cuando no es posible - por las características especiales del caso civil concreto- llegar a la verdad material o absoluta.

\section{La prueba de oficio y los principios dispositivo y de neutralidad}

Es posible que el foro académico pueda considerar que la incorporación de una prueba de oficio al interior del proceso afecta el principio dispositivo y el de neutralidad.

El principio dispositivo atribuye a las partes el impulso del proceso civil y, dentro de ello, la carga de probar, aun cuando la profesora Eugenia Ariano Deho (2003) sostenga con razón que "el probar no solo debe ser visto como una carga, sino también y principalmente como un derecho, pues existe un derecho a la prueba" (p. 169). Sin embargo, el ejercicio de ese derecho exige una carga: probar, pues no es automático. Los medios probatorios no se actúan solos. Hay que ejercer una actividad muy especial, como hemos referido anteriormente.

En tal sentido, y como quiera que todos los derechos exigen obligaciones para poder ejercerlos, en el caso del derecho a probar, las partes tienen la obligación de ejercer su actividad probatoria. Tienen la iniciativa y prerrogativa exclusiva de aportarlas. Es más, tienen la obligación de hacerlo desde el momento mismo en que postulan premisas a través de sus pretensiones y contrapretensiones. A tal efecto, deberán cumplir con los presupuestos de contenido de la prueba, como la idoneidad, utilidad y pertinencia.

La incorporación de la prueba de oficio no colisiona con el principio dispositivo, ya que - como se ha precisado- esta solo se justifica cuando no es posible para el juez realizar el análisis comparativo de la prueba actuada. Siendo una facultad del juez incorporar la prueba de oficio, ello es posible en tanto en cuanto las partes no pudieron acceder a la información necesaria faltante, por las diversas razones antes señaladas. Y, como quiera que el juez no puede decretar "empate" o "tablas", tendrá que realizar el ejercicio teórico de identificar el conocimiento faltante.

En cuanto a la imparcialidad, Ramírez Carvajal (2009) sostiene que cuando hablamos de imparcialidad hacemos referencia a la falta de designio anticipado o de prevención a favor o en contra de alguien; es decir, cuando se es imparcial, no se está a la expectativa de algo. Por lo tanto, en el caso del juez, se espera, frente a su imparcialidad, que obre y juzgue con rectitud. Luego, la imparcialidad presume la carencia de interés en el resultado de algo; la imparcialidad "es disposición, está directamente relacionada con el interés positivo o negativo que el juez pueda tener en la pretensión jurídica que debe decidir" (p. 102). 
Fajardo Mori (2012, pp. 167-168) precisa que, para garantizar la debida imparcialidad del juez, tienen que constar en el proceso las fuentes de prueba sobre las cuales posteriormente tendrá lugar su actividad probatoria. Agrega que debe restringirse únicamente a las fuentes probatorias que ya constan en autos; nunca debe investigar fuentes nuevas. Caso contrario, se compromete su imparcialidad porque sería incontrolable su fuente de conocimiento respecto de las pruebas que utilizará para resolver la controversia sometida por las partes.

La garantía procesal de la imparcialidad del juez debe distinguirse de la neutralidad, ya que son conceptos distintos desde una perspectiva pragmática. Así, Brey Blanco (2004, p. 49) refiere que, si neutralidad significase no implicación o desinterés y, en tal sentido, afectase a esa búsqueda de lo justo que debe caracterizar la acción del juez, lo más apropiado sería desechar rápidamente ese concepto. La neutralidad, al derivar de neutro, puede emplearse para aludir a aquello que carece de características expresivas o particulares. No puede desplazarse en ningún sentido. No realiza actividad alguna.

En el ámbito del proceso, el juez no desarrolla un papel pasivo. Por el contrario, su rol es activo al ser director del contradictorio. Más aún, al ser un sujeto procesal más, desarrolla actividades concretas en la conducción del proceso. Por lo tanto, el juez no es un agente neutro, sino imparcial.

De lo expuesto, se puede afirmar válidamente que, cuando el juez decide incorporar la prueba de oficio, tampoco vulnera el principio de imparcialidad, por cuanto no se trata de beneficiar a alguna de las partes, sino que "necesita" incorporar un conocimiento nuevo para resolver el caso concreto. Por lo demás, es claro que, dependiendo del conocimiento que se extraiga de la prueba de oficio, no se puede vislumbrar cuál será la parte que mejores intereses obtenga ni cuál no.

\section{CONCLUSIONES}

Como se planteó en la introducción de este trabajo, su propósito es proponer el empleo de una base teórica que incida sobre la aportación de la prueba de oficio al interior del proceso. Asimismo, se estableció que, siendo ello así, su hipótesis se centraría en conceptos igualmente teóricos, pero relacionados con el contenido del conocimiento del proceso, la relación de las premisas, la interiorización de los datos contenidos en los medios probatorios, su interrelación y la vinculación de estos.

Por consiguiente, no se ha incluido las características formales y materiales de la prueba de oficio precisadas en la norma, referidas por la doctrina o fijadas por la jurisprudencia, pues aquellas poseen una base principalmente material. Conducen al juez a seguirlas, pero no lo disuaden de un ejercicio científico procesal de adquisición del conocimiento necesario para encontrar la fórmula de decisión del conflicto. 
En tal sentido, se proponen las siguientes conclusiones:

1. No todos los procesos civiles se rigen estrictamente por una fórmula procesal única e invariable. Dependiendo de las características de cada caso, el proceso tendrá igualmente mayor o menor grado de complejidad. Por ende, a mayor grado de complejidad y por la imprecisión jurídica que lo caracterice, mayor será la dificultad para su solución.

2. En el tipo de procesos complejos e instrumentales, el contradictorio será siempre abierto en todas las etapas del proceso y será de mayor intensidad en la etapa probatoria.

3. En estos procesos, la finalidad será dar la solución adecuada al conflicto a través de una fórmula jurídica en justicia, dependiendo de la demostración de las premisas planteadas por las partes. Por ello, la verdad material será una finalidad imprecisa y puede agotar los esfuerzos procesales en vano, perjudicando la salud del proceso.

4. La máxima aproximación de certeza respecto de las premisas debidamente demostradas será la finalidad del proceso cuando este, por sus características, es complejo.

5. Los medios probatorios proporcionan datos e información que deben ser extraídos de su contenido mediante su actuación y contradicción. Benefician a aquella parte que pudo acceder mejor al conocimiento contenido en ellos, aunque no hayan sido aportados por ella.

6. La actividad probatoria implica una técnica procesal de prueba vs. contraprueba, en la cual se desarrollarán las mejores habilidades legítimas y legales que exige la buena conducta procesal, tanto para acreditar los dichos como para desacreditar los medios de la parte contraria.

7. En dicha técnica, los medios impugnatorios de la oposición y la tacha constituyen herramientas válidas de refuerzo cuando deban proceder, y no han de ser desestimadas por quien puede proponerlas, pues ello es contrario a su sentido.

8. Concluida la etapa probatoria, y previo al desarrollo de razonamiento que justifique la sentencia, el juez, al proceder a valorar de manera conjunta los medios probatorios, deberá obtener el conocimiento de información relevante de cada medio probatorio actuado, para posteriormente vincularlos a través de un análisis comparativo.

9. El resultado obtenido de la información extraída de los medios probatorios para la vinculación correspondiente entre ellos formará una cadena de inferencias, 
cuyo resultado será la demostración de la hipótesis propuesta por la parte que estuvo en mejor condición de demostrar la certeza de sus premisas.

10. Cuando no es posible armar una cadena de inferencias, por falta de un conocimiento relevante y necesario para arribar a una conclusión lógicamente cierta, el juez deberá encontrar el elemento faltante y que se derive de la fuente de la prueba, para incorporarla de oficio al proceso.

11. La prueba de oficio aportada al proceso tendrá las mismas condiciones y características de actuación y contradicción, de acuerdo con el principio de comunidad y de igualdad.

12. La decisión del juez de incorporar una prueba de oficio debe sostenerse sobre una base teórica de razonabilidad en la búsqueda del conocimiento para introducirlo al proceso, lo que configura la gnoseología inductiva procesal.

\section{REFERENCIAS}

Alvarado Velloso, A. (2016). Los conceptos de instancia y acción procesal como instancia bilateral. En C. Gómez Fröde y M. E. Briseño García Carrillo (Coords.), Nuevos paradigmas del derecho procesal (pp. 61-90). Ciudad de México: UNAM/Instituto de Investigaciones Jurídicas.

Amato, S. (2000). Del derecho al derecho natural. En R. Rabbi-Baldi Cabanillas (Coord.), Las razones del derecho natural (pp. 111-136). Buenos Aires: Ábaco.

Andrés lbáñez, P. (1992). Acerca de la motivación de los hechos en la sentencia penal. Doxa: Cuadernos de Filosofía del Derecho, 12, 257-300.

Andrés Ibáñez, P. (1998). "Carpintería" de la sentencia penal (en materia de "hechos"). Revista del Poder Judicial, 49, 393-428.

Apolín Meza, D. L. (2004). Apuntes iniciales en torno a los límites en la aplicación del aforismo iura novit curia y la reconducción de pretensiones. lus et Veritas, 14(29), 32-40.

Ariano Deho, E. (2003). El derecho a la prueba y el Código Procesal Civil. En Problemas del proceso civil. Lima: Jurista Editores.

Ausín, T., y Peña, L. (2011). Premisa/Conclusión. En L. Vega Reñón y P. Olmo Gómez (Eds.), Compendio de lógica, argumentación y retórica (pp. 479-481). Madrid: Trotta.

Brey Blanco, J. L. (2004). Los jueces y la política. ¿Imparcialidad/neutralidad versus compromiso democrático? Foro. Revista de Ciencias Jurídicas y Sociales, Nueva Época, (00), 37-67. 
Calamandrei, P. (1973). Instituciones de derecho procesal civil (Trad. S. Sentís, 2. ${ }^{a}$ ed.). Buenos Aires: Ejea.

Corcoran, J. (2011). Deducción/Deducibilidad. En L. Vega Reñón y P. Olmo Gómez (Eds.), Compendio de lógica, argumentación y retórica (pp. 168-169). Madrid: Trotta.

Corte Suprema de Justicia de la República. (2015). Acuerdo Plenario N. ${ }^{\circ}$ 04-2015/ CIJ-116. Lima: Fondo Editorial del Poder Judicial. Recuperado de https:// www.pj.gob.pe/wps/wcm/connect/086ac7004e1457a084f1f448a12af05b/ IX+Pleno+Supremo+Penal.pdf?MOD=AJPERES

Couture, E. (1993). Derecho procesal civil. Fundamentos del derecho procesal civil. Buenos Aires: Depalma.

Delgado Suárez, C. (s. f.). Prueba de oficio y derecho al contradictorio. Agnitio. Recuperado de http://agnitio.pe/articulo/prueba-de-oficio-y-derecho-al-contradictorio/

Devis Echandía, H. (1981). Teoría general de la prueba judicial. Buenos Aires: Zavalia Editor.

Devis Echandía, H. (2000). Compendio de la prueba judicial (tomo I). Buenos Aires: Rubinzal Culzoni Editores.

Devis Echandía, H. (2002). Teoría general de la prueba judicial (tomo 2). Buenos Aires: Zavalia Editor.

Fajardo Mori, M. (2012). Aspectos relevantes sobre la iniciativa probatoria del juez civil. Derecho \& Sociedad, (38), 163-168.

Miranda Estrampes, M. (2012). La prueba en el proceso penal acusatorio. Reflexiones adaptadas al Código Procesal Penal peruano de 2004. Lima: Jurista Editores.

Monroy Gálvez, J. (1992). La postulación del proceso en el Código Procesal Civil. THËMIS. Revista de Derecho, (23), 33-42.

Peyrano, J. W., y Chiappini, J. (1985). El proceso atípico. Buenos Aires: Editorial Universidad.

Ramírez Carvajal, D. M. (2009). La prueba de oficio: una perspectiva para el proceso dialógico civil. Bogotá: Universidad Externado de Colombia.

Salas Villalobos, S. (2014). Saneamiento procesal y fijación de puntos controvertidos para la adecuada conducción del proceso. Revista Jurídica Thomson Reuters, (62), $11-24$.

Taruffo, M. (2013). La verdad en el proceso. Derecho \& Sociedad, (40), 239-248.

Vega, L. (2011). Inferencia. En L. Vega Reñón y P. Olmo Gómez (Eds.), Compendio de lógica, argumentación y retórica (pp. 297-301). Madrid: Trotta. 
